\title{
El moviment coral a la província de Castelló
}

\author{
Arantxa Martínez Gavara (arantxamg76@gmail.com) \\ Cor de la Generalitat Valenciana
}

\section{Introducció}

L'home, com a espècie social que és, ha sentit sempre, des dels temps de la prehistòria, la necessitat de cantar en grup. Fa molts segles que el cant col-lectiu existeix, associat tant a actes profans com religiosos, i en aquest sentit es pot considerar una de les primeres manifestacions socials. Les reunions corals tenien lloc ja a l'antiga Grècia, no eren com les coneixem hui en dia però sí s'entenien com a mitjà d'expressió i es donaven amb un propòsit social.

També les agrupacions corals modernes tal com les coneixem cometen aquesta necessitat social de cantar col-lectivament. En principi, al seu naixement, de caràcter civil amb uns propòsits més concrets i que amb el temps s'han diversificat sobretot en forma $i$ naturalesa, també amb unes finalitats diferents. Això sí, sense perdre l'essència socialitzant que les ha caracteritzat des de sempre.

No en tots els nuclis demogràfics i socials ha experimentat el cant coral la mateixa projecció i divulgació. En el cas que ens ocupa, el de la província de Castelló, no ha tingut aquest moviment l'estímul ni el pes social que ha tingut, per exemple, a Catalunya o el País Basc. Però, poc a poc, aquest tipus d'expressió artística ha anat calant en els membres d'aquestes comunitats fins a ser un acte social ben important.

\section{Origen del moviment coral}

Al llarg dels segles la música religiosa a Europa ha afavorit, d'una manera o d'una altra, el desenvolupament de la pràctica coral. Amb el naixement de nous valors socials $\mathrm{i}$ culturals es crea també un nou concepte per a la pràctica coral a Europa. A principis del segle XIX, primer a Anglaterra amb agrupacions de veus masculines i després a Europa central, ja van sorgir les primeres agrupacions corals de caràcter no professional i profà al compàs dels nous moviments democràtics i liberals, l'associacionisme, els moviments obrers i la revolució industrial.

Aquest moviment coral d'aficionats es propaga ràpidament per tot Europa. Cobra especial importància a França amb el mètode d'aprenentatge de solfeig a través del cant coral introduït per Bocquillon-Wilhem, que al 1833 va fundar un cor obrer d'aficionats amb components només masculins anomenat Orphéon. Aquest tipus d'agrupació es propagarà ràpidament per tota França i també als països veïns. A l'Estat Espanyol tindrà el seu reflex ja a la segona meitat del segle XIX i cobrarà especial importància a Catalunya.

A la primera meitat del segle XIX es produeix a l'Estat Espanyol un èxode de les zones rurals a les ciutats degut als canvis que la industrialització provoca en la societat. Aquestes transformacions no només afecten als processos de producció sinó també a les formes de 
vida. La Revolució Industrial va derivar en unes condicions de vida i laborals deplorables per als obrers. S'inicien mobilitzacions obreres en defensa de millores laborals i polítiques. L'educació entre la classe obrera era pràcticament nulla i la taxa d'analfabetisme molt elevada. En aquest context històric és en el que naixen i es propaguen les primeres societats corals.

La figura de Josep Anselm Clavé1 també naix i creix enmig de totes aquestes circumstancies socials. A Barcelona els llocs d'oci per a les classes populars eren cafès i tavernes on acudien després de les llarguíssimes jornades laborals. Allí s'interpretaven cançons considerades immorals i de mal gust per part de les classes socials més benestants. Clavé compartia la baixa estima i el menyspreu que tenien aquestes cançons i considerava que aquesta situació anava lligada a la precària situació en la que es trobava la classe obrera. Va pensar que era necessari canviar aquesta situació i ell mateix escriu a El Metrónomo ${ }^{2}$ al 1863 (Poblet, 1973: 11):

\begin{abstract}
Aleshores vaig girar els ulls al meu voltant i vaig preguntar-me quins entreteniments s'oferien a l'obrer en les hores de descans, i es presentà a la meva vista l'espectacle repugnant del cafetins, catau de dones de bordell i de dropos, que amb l'esquer de les cançons lascives atreien els incauts a la degeneració i a la misèria. Vaig fixar-me en aquells cants tan en voga entre el poble, i de moment em semblà impossible reformar tot allò corromput. Però la fe i la perseverança inseparables de totes les accions de la meva vida van donar-me el triomf, momentani si voleu, però d'una immensa transcendència per als meus projectes ulteriors.
\end{abstract}

La seua idea era millorar les condicions de vida de la classe treballadora, així com la formació cultural, mitjançant la música i més concretament la pràctica coral, sempre amb un esperit de reivindicació social. Així es va crear la primera societat coral de l'Estat Espanyol. ${ }^{3}$

Al 1845 Clavé i un grup de joves formen una rondalla, L'Aurora, que serà el ferment de la societat coral La Fraternitat ${ }^{4}$ fundada el 2 de Febrer de 1850 (Carbonell, 1994: 70; Carbonell, 1999a: 28; Gargallo, 2007: 17; Guansé, 1966: 31; Nagore, 1999: 23; Poblet, 1973: 75; Soriano, 1865: 34; Trenc, 1994: 81). Al 1857 La Fraternitat canvia el seu nom pel de Sociedad Coral de Euterpe (Carbonell, 1994: 72; Gargallo, 2007: 17; Guansé, 1966: 57; Nagore, 1999: 24; Poblet, 1973: 121; Trenc, 1994: 83). Un dels biògrafs de Clavé, Domènec

\footnotetext{
${ }^{1}$ Josep Anselm Clavé i Camps naix el 21 d'abril de 1824 a la Plaça de Medinaceli, barri de la Mercè. És fill d'un magatzemista de fustes i té dos germans, Francesc i Antoni. Sa mare, Agnès Camps i Camps era una persona culta que tocava el clavecí i dominava el francès.

${ }^{2}$ Setmanari publicat durant els anys 1863-1864 per l'Asociación Euterpense, primera entitat federativa que reunia a les societats corals claverianes, fundada el 1860 i presidida pel mateix Clavé. Aquest setmanari era el portaveu de l'Asociación Euterpense i de totes les societats corals associades. Clavé ja va iniciar la publicació, el 15 de maig de 1859, d'una revista setmanal de quatre pàgines que s'anomenava El Eco de Euterpe abans de la fundació d'El Metrónomo que va tindre molt curta durada, des de gener de 1863 fins a desembre del mateix any. ${ }^{3} \mathrm{Al} 1863$ es va produir un dur enfrontament entre Josep Anselm Clavé i els germans Tolosa respecte a quina va ser realment la primera agrupació coral de tot l'Estat Espanyol. Clavé va fundar la societat coral La Fraternitat al 1850. Joan i Pere Tolosa van crear al 1853 l'Orfeón Barcelonés seguint els mètodes de Wilhem.

${ }^{4}$ La Fraternidad és la primera societat coral obrera de l'Estat Espanyol a imitació de les ja existents a la resta d'Europa. Hem de tindre en compte que ja existien formacions religioses i vinculades al teatre de caire professional.
} 
Guansé, a «Josep Anselm Clavé: apòstol, agitador i artista» (Guansé, 1966: 30) ens explica les intencions de Clavé:

El contacte amb els minyons de "L'Aurora", l'experiència que realitzava amb ells, van fer comprendre aviat a Clavé tot el que podria ésser fet per millorar la condició moral, i àdhuc material, dels treballadors si emprenia aquella obra més en gran, i es va prometre a ell mateix de consagrar-hi la vida.

\section{Implantació del moviment coral i expansió a la província de Castelló (1850-1870)}

Dins d'aquest període podem diferenciar dues etapes, una que coincideix amb la primera dècada i que anomenem d'implantació i una altra durant la segona dècada que seria de difusió.

La Fraternitat serà la primera societat coral obrera de tot l'Estat Espanyol; debuta el 14 d'agost de 1850 al carrer Sant Miquel de la Barceloneta. En aquesta societat el cant coral i la música eren més bé un mitjà; la finalitat i la intenció amb la que Clavé va fundar La Fraternitat era sense dubte una altra, la instrucció i l'educació moral dels obrers per tal de dignificar les condicions en les que vivien. El musicòleg Mariano Soriano Fuertes escriu sobre la figura de Clavé (amb qui mantenia una forta amistat) a Memoria sobre las sociedades corales en España (Soriano, 1865). En aquesta obra remarca els aspectes socials i organitzatius de les societats i incideix en la importància de la pràctica del cant coral com a forma de lleure i cultura (Soriano, 1865: 41):

Las sociedades corales son útiles al desarrollo civilizador de los pueblos, y las deseo para mi patria. En Clavé encuentro genio, entusiasmo y honradez, y con honradez y entusiasmo le he defendido y le defiendo. Si criticado soy, la crítica no me asusta cuando mi conciencia está tranquila, y los resultados favorables al objeto civilizador y bueno que defiendo, son la causa de tan envidiable tranquilidad.

Al 1857, després d'una sèrie d'incidents, La Fraternitat es transforma en la Sociedad Coral de Euterpe. La forta incidència social de les entitats claverianes va fer que es propagaren ràpidament més enllà de la ciutat de Barcelona. Clavé estava en contacte amb totes elles i aquestes, malgrat que es negava a fer política dins els seus cors; a més de cantar les seues lletres i la seua música, seguien també els seus ensenyaments morals: «El que ell pretenia com a suprem ideal era ben senzill: fer que l'estament treballador prengués consciència de la dignitat i noblesa del treball i que no prosseguís privat dels beneficis de la civilització i de la cultura» (Guansé, 1966: 58)

Però van existir altres fenòmens corals contemporanis a aquest $\mathrm{i}$ totalment independents.

Paral-lelament al moviment creat i organitzat per Clavé es va oposar el dels germans Joan i Pere Tolosa ${ }^{5}$ que van fundar al 1853 l'Orfeón Barcelonés seguint el mètode Wilhem.

\footnotetext{
${ }_{5}^{5}$ Joan Tolosa naix a Barcelona al 1818. Després d'estudiar solfeig i violí a la seua ciutat natal va marxar a Marsella i a París on va estudiar harmonia i contrapunt.
} 
Al 1863 es va produir una forta polèmica entre Clavé i els germans Tolosa sobre qui va ser el primer a introduir el cant coral a Barcelona, ja que tots dos s'atribuïen el mèrit d'haver fundat la primera entitat coral de la Península. Darrere d'aquesta lluita trobem amagat un enfrontament estètic i ideològic. Mentre per a Clavé allò fonamental era l'aspecte social i humanitari de l'acció, o siga, la funció educativa i moralitzant del cant coral on el resultat musical i tècnic es convertien en secundaris, per als germans Tolosa era totalment el contrari amb una concepció més tècnica i professional en la que primaven els resultats artístics.

Entre 1860 i 1870 la xifra d'entitats corals a Catalunya es dispara i comença a expandirse cap a altres indrets geogràfics. Es possible que en alguns llocs de l'Estat l'origen del moviment coral haja estat independent del català.

A diferència de Catalunya on molts dels cors ja s'havien format en la dècada anterior, al País Valencià és en aquest període on van aparèixer els primers cors i orfeons. Al 1864 l'Asociación Euterpense de cors de Clavé estava formada per 85 societats corals, totes elles catalanes menys dues: una a Saragossa i una altra a Vinaròs, la Sociedad Coral El Maestrazgo, la primera societat coral del País Valencià fundada el 22 de setembre de 1862 (Soriano, 1865: 93).

La polèmica Tolosa-Clavé es va projectar en certa manera a terres valencianes amb la creació d'El Maestrazgo a Vinaròs (seguidora dels postulats de Clavé) i l'Orfeón Valenciano a València (que seguia el model de l'Orfeón Barcelonés i el mètode Wilhem), el mateix any (Carbonell, 2000a: 182).

\section{Crisi (1870-1890)}

El moviment coral espanyol experimenta una recessió a partir de 1865, justificada per la inestabilitat política i econòmica. Fins al 1875 la creació de societats corals és quasi inexistent. Malgrat les dificultats, Ernesto Villar Miralles va fundar al 1882 a Vinaròs un cor de 40 veus. Al llarg de la dècada de 1880 ens trobem amb una recuperació que va culminar en una etapa de total esplendor a la dècada dels 90.

Al 1873, dues setmanes després de la proclamació de la República, el nou règim va designar Clavé Governador Civil de Castelló de la Plana, càrrec que va exercir prop de cinc mesos. A l'Arxiu de la Diputació de Castelló a la Gaceta de Madrid es troba el nomenament del càrrec: «El Gobierno de la República ha tenido a bien nombrar Gobernador civil de la provincia de Castellón a D. José Anselmo Clavé. Madrid veinticinco de Febrero de mil ochocientos setenta y tres». Firma el president del Govern executiu Estanislau Figueres. ${ }^{6}$

Sabem que Clavé va escriure en aquesta ciutat la seua última composició coral, Goigs i planys, possiblement la seua obra mestra. Des del començament de la República, Clavé va caure greument malalt i va morir el 24 de febrer de 1874 (Vinyes, 1999: 54). El seu pas per Castelló podria haver anat lligat a alguna activitat coral però no va ser així.

Malgrat la poca activitat coral, pràcticament nul·la, d'aquest període es va crear un cor a Vinaròs. Ernesto Villar Miralles (1852-1916) (Adam, 2003: 832) el va fundar i dirigir, a més de la Banda i una orquestra, de 1882 a 1887. Aquest cor, de 40 veus, va fer una actuació a Vinaròs al 1884 (Albiol, 2006: 17).

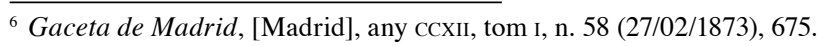




\section{Consolidació (1890-1900)}

L'associacionisme, i en part el moviment coral, està vinculat en gran mesura a la societat industrial. A diferència d'alguns països europeus, a l'Estat Espanyol la industrialització i el capitalisme no seran una realitat fins ben entrat el segle xx. Només alguns territoris, com és el cas de Catalunya, van experimentar aquests canvis en la societat i la economia. Però a finals del segle XIx Espanya era encara una societat predominantment agrària i aquest era també el cas de la província de Castelló.

Entre 1890 i 1900 trobem un període de consolidació: a nivell nacional es produeix una autèntica eclosió del moviment coral, sobretot a les zones on el nacionalisme-regionalisme i el moviment obrer tenien més força; podríem estar parlant d'una edat d'or del coralisme (Nagore, 1999: 26).

Després d'un període de decadència de les societats claverianes a la mort del mateix, es va experimentar al 1890 un nou ressorgiment amb els mateixos valors i sentiments però amb un canvi en quant a la qüestió artística que començava a prendre més valor. A València va començar a valorar-se la figura de Clavé en contraposició a la de Tolosa i es va fundar l'Asociación de Coros de Clavé. Encara que més tard, al 1896, es crearia, en oposició a la institució claveriana, l'Asociación coral de la Región Valenciana (Galbis, 2006: 254-255)

Al 1895 existien, a la província de Castelló, associacions corals a Castelló, Sogorb i, per suposat, a Vinaròs. Uns anys després, debutava l'Orfeón Republicano, també de Vinaròs. En trobem aquesta mostra a Boletín Musical: ${ }^{7}$

Hace ya más de dos años que en las columnas de este periódico, empezamos la propaganda de nuestros ideales y aspiraciones en pró de la institución coral de la región valenciana, [...]

Durante este transcurso de tiempo, han quedado definitivamente constituídos los orfeones de Valencia, Requena, Buñol, Segorbe, Castellón, Vinaroz, [... $]^{8}$

Concretament al 1899, debutava a Vinaròs, al Festival musical de la plaça de bous, l'Orfeón Republicano. ${ }^{9}$ Aquesta agrupació pertanyia al Centro Instructivo Republicano que s'havia fundat recentment i en el saló d'actes del qual va actuar aquest orfeó a les fires de 1901.

\section{Des de l'inici del segle $\mathrm{xx}$ al final de la dictadura (1900-1975)}

Amb el canvi de segle les associacions corals es van diversificar tant en la composició (es crearen més cors mixtos) com en el repertori, la tendència política, religiosa, popular, ... (Nagore, 1999: 28). El moviment coral del que hem parlat va ser molt important pel moment en el que es va instaurar i pel caràcter associatiu, socialitzant i educador, a més de musical. Però aquest tipus d'agrupacions no van ser ni molt menys les més nombroses. A Castelló va predominar l'activitat coral de caire religiós per damunt de les agrupacions civils.

\footnotetext{
${ }^{7}$ Boletín Musical és una revista valenciana que va començar a publicar-se al 1992. La podem considerar una font important per a conèixer l'activitat coral durant aquest període.

${ }^{8}$ Boletín Musical, [València], n. 62 (30/07/1895), 473.

${ }^{9}$ Diario de Castellón: Periódico político, de noticias y anuncios, [Castelló], (10/06/1899); (28/06/1899).
} 
Cal destacar la figura de Vicent Ripollés ${ }^{10}$ un dels pilars més forts al nostre país de la reforma del Motu Proprio, signat per Pius X al 1903. Són una sèrie de normes sobre les que s'hauria de regir la Música Litúrgica atesos els abusos i excessos que, segons l'Església, es venien cometent en les misses i litúrgies. Aquesta reforma va influenciar d'alguna manera l'activitat coral senyalant, entre altres coses, la preferència del cant gregorià i la polifonia clàssica, i sobretot va promoure la creació de les anomenades Scholae Cantorum.

Al 1904 l'entitat de la província La Unión de la Almunia es va sumar a l'Associació Euterpense de Cors de Clavé (Aviñoa, 2000: 182). De tota la província de Castelló, potser Vinaròs ha estat la ciutat més activa en quant al cant coral es refereix. No només ha aportat diverses agrupacions corals sinó que ha promogut concerts i actes oficials en els que la música en general i, en concret, la coral han intervingut com a part important i necessària. Al 1928 fa el seu debut, de nou a Vinaròs, la Massa Coral del Centre Instructiu Republicà formada per unes 40 veus, totes elles masculines (Albiol, 2006: 17).

Durant els anys que va durar la Guerra Civil l'activitat coral a tot el país va quedar paralitzada; només finalitzada aquesta es tornarà a organitzar però d'una manera lenta $\mathrm{i}$ progressiva i amb característiques ben diferents. Després de la guerra, ja en la dictadura, algunes societats es van decantar per reprendre i cultivar un repertori com el de la sarsuela. També la influència i el poder que, en tots els aspectes, va adquirir l'Església Catòlica i els nous valors del franquisme van marcar la reorganització d'alguns cors i la creació d'altres de nous. Així doncs, es va fomentar la fundació de cors parroquials i molts d'ells ja existents van passar a dependre d'institucions com ara la Sección Femenina o l' Obra Sindical Educación y Descanso (Tomás, 1992: 452).

El primer cor fundat després de la Guerra Civil va ser la Schola Cantorum de Castelló de la Plana en 1939 (Tomás, 1992: 452). Aquesta es va convertir en la coral religiosa més important de tota la província ja que abastava un ampli repertori de polifonia clàssica $\mathrm{i}$ de misses. Aquesta formació va iniciar al 1979 un segon període i es va decidir a incloure veus femenines i a abordar un repertori de caràcter profà, amb una especial dedicació a la música popular (Galbis, 2006: 257).

A partir dels anys 50 es va experimentar, a tot el territori nacional, un creixement de l'activitat coral que s'incrementaria a partir de la dècada dels 70. Aquest despertar coral es va experimentar amb un cert retard al País Valencià on es va iniciar a partir dels anys 60 .

Una de les agrupacions més estables i actives de la província de Castelló ha sigut la Coral Polifònica Benicarlanda fundada al 1951 a Benicarló. Aquesta agrupació ha assolit un gran prestigi i reconeixement. Actualment està formada per unes 55 veus mixtes i compta amb dues seccions, una juvenil: la Coral Kylix; i una altra infantil: la Coral Petiquillo. ${ }^{11}$

La localitat de La Vall d'Uixó és un exemple de tradició musical, no només referit a les bandes de música, també en relació al cant coral. Bona mostra d'això és que al 1955 va ser fundat l'Ateneu Musical Schola Cantorum per En Miguel Arnau Abad. Amb un grup de joves va formar un cor de veus masculines que en principi estaria vinculat a la Parròquia de Nostra Senyora de l'Assumpció. La intenció inicial del seu fundador era la labor humanitària mitjançant la música, a l'estil de les agrupacions claverianes. En

\footnotetext{
${ }^{10}$ Nascut a Castelló el 20 de novembre de 1867 i mort a Rocafort el 19 de març de 1943.

${ }^{11}$ Programa del Concert de Sant Jordi, Barcelona, Palau de la Música Catalana (22/04/2007).
} 
l'actualitat aquesta entitat compta amb una Escola de Música, una Banda Simfònica, una Banda Juvenil, un Cor Polifònic, una Orquestra i un Quadre Artístic. ${ }^{12}$

A la mateixa població es va fundar, al 1957, el Cor Parroquial del Sant Àngel Custodi, format dins la parròquia que porta el mateix nom. A diferència de l'anterior entitat, que en l'actualitat està totalment desvinculada de la parròquia, aquesta continua lligada a aquella, al si de la qual es va crear.

\section{Des de la transició democràtica fins a l'actualitat (1975-2012)}

A partir de 1975 l'ambient d'apertura social que propiciava la democràcia va impregnar també el moviment coral. Hi ha una tendència generalitzada als cors de veus mixtes. Destaca també la varietat de tipus d'agrupacions que apareixen en aquest temps: cors parroquials, escolanies, scholae cantorum, cors de cambra, polifònics, universitaris, populars i inclús alguns que aborden repertoris simfònic-corals. El creixent grau de mobilitat i comunicació ha afavorit també la participació dels cors en concerts, concursos, festivals, etc., a nivell nacional i internacional (Nagore, 1999: 29).

A la província de Castelló ha sigut en aquesta última etapa on l'activitat coral ha crescut i s'ha desenvolupat de manera més intensa. La quantitat de cors que s'han arribat a crear és molt més significativa que als altres períodes. L'activitat coral ja no és exclusiva dels nuclis urbans més grans i importants, sinó que s'ha anat estenent a les poblacions més menudes en les que sí podem afirmar que l'església ha jugat un paper fonamental. Com ja hem dit, a la província de Castelló han predominat les agrupacions corals de tipus religiós i, llevat de poblacions xicotetes on possiblement la densitat demogràfica és prou baixa, en moltes localitats existeix al menys un cor vinculat a una parròquia.

És destacable la intensitat de l'activitat coral a determinades poblacions. A Castelló de la Plana, per ser la capital i la ciutat més important de la província, és on es concentren en aquest període la major part de les agrupacions i algunes de les més significatives. Mereixen especial menció nuclis com ara Borriana, Benicarló, Vinaròs i La Vall d'Uixó on, a més de comptar amb notables entitats corals, hi han sorgit escoles corals i agrupacions de caire infantil i juvenil molt dinàmiques i implicades en la funció social i educativa del cant coral.

En els últims anys hem apreciat la tendència a formar cors de cambra. Aquest fenomen s'ha produït amb més èmfasi a les comarques de La Plana Alta i La Plana Baixa, amb components joves i, sense ser professionals, amb coneixements musicals que proporcionen més qualitat i la possibilitat d'abordar un repertori més difícil i amb uns resultats considerablement més notables.

\section{Agrupacions més importants de la província de Castelló en l’actualitat}

\section{Coral Polifònica Benicarlanda}

La Coral Polifònica Benicarlanda és, de les agrupacions corals actuals, la més antiga i una de les més importants. Es va fundar al 1951 i el seu primer director va ser Pedro Mercader, un tenor del Gran Teatre del Liceu de Barcelona. És una coral mixta

$\overline{12<\text { http://www.lascholacantorum.org/?q }}=$ node/23>, [data de consulta: 11 d'agost de 2008] 
i en l'actualitat compta amb unes 55 veus. Abasta un repertori extens que va des de la polifonia religiosa a cors d'òpera i sarsuela, passant per música popular valenciana i estrangera. Pertany a la Federació Catalana d'Entitats Corals i a la Federació de Cors de la Comunitat Valenciana. Aquesta agrupació compta amb una secció Juvenil Coral Kylix dirigida per Clara Ruíz i una secció Infantil Coral Petiquillo dirigida per Sònia Ferrer.

\section{Cor Polifònic de l'Ateneu Musical Schola Cantorum}

Aquest cor comença la seua trajectòria en 1955, fundat per Miguel Arnau Abad i animat per mossèn Francisco Ballester i mossèn José Herrero. En principi es tractava d'un cor masculí vinculat a la Parròquia de Nostra Senyora de l'Assumpció. Al 1967 va deixar de ser un cor parroquial i es va deslligar de la Parròquia de l'Assumpció per a crear la societat que coneixem avui en dia, l'Ateneu Musical Schola Cantorum, a l'empar de la Llei d'Associacions Civils de l'any 1965. En l'actualitat el cor s'ha convertit en polifònic i és una secció més dins el que seria la societat musical, ja que conviu amb una Banda Simfònica, una Banda Juvenil, una Orquestra i un Quadre Artístic. En aquests moments la societat coral no està federada.

\section{Coral Vicent Ripollés}

Aquesta societat coral és possiblement l'agrupació més reconeguda de tota la província de Castelló. Va ser fundada a l'octubre de 1978 pel seu director Juan Ramón Herrero (1933-1997), un dels músics més importants de Castelló en la segona meitat del segle xx, amb el nom Coral Polifònica Castellonense. Poc després va passar a nomenar-se com ho fa en l'actualitat. La Coral Vicent Ripollés és polifònica i el nombre de membres actual és aproximadament de 50 cantaires. Pertany també a la Federació Catalana d'Entitats Corals i a la Federació de Cors de la Comunitat Valenciana.

\section{Coral Borriolenca}

La Coral Borriolenca va ser fundada al 1979 i el seu director és, des dels seus inicis, Henri Bouché Peris. És una coral polifònica molt vinculada a la vida de la localitat. Segons les dades de les que disposem, no està federada.

\section{Coral Sant Jaume}

Aquesta coral naix l'any 1980. El seu director actual és Alfredo Sanz que està al front de la formació des de 1995. Està formada per unes 35 veus mixtes i el seu repertori inclou obres de diversos tipus i estils, religioses, populars, simfòniques..., però és en la interpretació d'obres d'autors contemporanis on es troben més còmodes. És membre de la Federació de Cors de la Comunitat Valenciana.

\section{Coral García Julbe}

La Coral García Julbe, igual que l'anterior formació, es va fundar l'any 1980. A l'inici del seu recorregut aquesta formació s'anomenava Coral Vinarosense, però en un homenatge al músic vinarocenc Vicent Garcia Julbe (1903-1997), el 10 de març de 1984, en què va 
participar també la Coral Vicent Ripollés, va canviar el seu nom pel de l'homenatjat (Ripollés, 2004: 73-74), que és el nom amb el qual es coneix en l'actualitat. Aquesta agrupació, igual que algunes altres de la província, també pertany a la Federació Catalana d'Entitats Corals i a la Federació de Cors de la Comunitat Valenciana.

\section{Coral Borrianenca}

Aquesta formació va fer la seua presentació en públic l'any 1984 sota la direcció de José Ramón Calpe. És un cor de veus mixtes i actualment està format per uns 22 components. Ha cultivat tots els estils musicals i en el seu repertori inclou algunes de les obres simfòniccorals més destacades de la història de la música. Forma part de la Federació Catalana d'Entitats Corals.

\section{Coral Polifònica de Peníscola}

Aquesta agrupació coral del Baix Maestrat naix al 1986 sota el nom d'Agrupació Coral Tremenda Cantata. Va ser fundada per mossèn Laureano Gil i el músic i director establert a Peníscola Vittorio Cacciattori. Al 2005 canvia el seu nom pel que té en l'actualitat, Coral Polifònica de Peníscola. És una agrupació coral mixta i els tipus d'actuacions i el repertori són molt diversos. Segons les dades de les que disposem, no està federada.

\section{Orfeó Vinarossenc}

L'Orfeó Vinarossenc es va fundar l'any 1988. És també una agrupació coral amateur de veus mixtes com la majoria de les que trobem al llarg de la nostra geografia. Participa de manera activa en la vida de la ciutat de Vinaròs collaborant en actes oficials, festes, festivals, etc. Habitualment també realitza intercanvis amb altres cors de la comarca $\mathrm{i}$ de Catalunya. Aquesta agrupació també forma part de la Federació Catalana d'Entitats Corals i de la Federació de Cors de la Comunitat Valenciana.

\section{Orfeó Universitari Jaume I}

L'Orfeó Universitari Jaume I fa el seu debut el 29 de maig de 1992 en l'acte de clausura de l'any acadèmic. Des dels seus inicis ha estat dirigit per José Luis Palacios, Telmo Campos, Oscar Ventura, i actualment per Toni Planelles. És un cor mixt format per uns 40 cantaires, membres de la comunitat universitària. El repertori que interpreten va des de la música antiga a la contemporània, incloent peces de música popular moderna. Concedeixen especial importància a la música escrita en valencià i als autors valencians com la de la castellonenca Matilde Salvador. És també membre de la Federació Catalana d'Entitats Corals i de la Federació de Cors de la Comunitat Valenciana.

\section{Coral Juan Ramón Herrero}

Aquesta formació és probablement de les més joves de la ciutat de Castelló ja que la fundació data d'abril de 2000 i el començament de la seua trajectòria és octubre del mateix any. El seu director és Ricardo Macho Besé. És una coral formada per unes 30 veus mixtes que ha aconseguit en poc de temps abordar un repertori variat que comprèn des de la música antiga a la polifonia del segle xx. Pertany, com altres entitats, a la Federació Catalana d'Entitats Corals i a la Federació de Cors de la Comunitat Valenciana. 


\section{Conclusió}

Tothom pot pensar que el moviment coral a la província de Castelló hauria d'haver gaudit d'una magnitud i un esplendor, si més no tan important com el de Catalunya, sí similar en dimensions donada la proximitat geogràfica i la ràpida influència que van tindre les societats claverianes a Vinaròs a través de la Sociedad Coral El Maestrazgo. Però podem veure per les dades de les que disposem que no ha sigut així. Sí que és veritat que al llarg del anys aquest moviment s'ha anat consolidant poc a poc a la província i que Clavé i les seues societats han sigut decisives.

Podem atribuir aquest fenomen a que la societat de la província de Castelló és predominantment agrícola i que, com hem vist, el moviment coral ve lligat a la revolució industrial. Bàsicament les agrupacions corals, inclús la majoria de les que trobem actualment, es concentren en nuclis de població més nombrosos. Que la província de Castelló, sobretot a l'interior, es tracte d'una societat preeminentment rural i de baixa densitat demogràfica ens fa pensar en les causes de que el que va començar a Vinaròs al 1862 no haja tingut la repercussió suposada.

Segurament aquesta situació, ajudada per l'existència de les bandes de música, que sí han fet una funció d'estructuració social i moral de les distintes comunitats, ha fet que el moviment coral no haja sigut com cabria esperar.

\section{BIBLIOGRAFIA}

Adam Ferrero, B. (2003): 1000 Músicos Valencianos, València, Sounds of Glory.

Aguilar Ródenas, C. (1997): Educació i Societat a Castelló al llarg de la II República, Castelló, Diputació de Castelló.

Albiol Vidal, S. (2006): La Banda "La Alianza" y la música en Vinaròs. Los primeros años de la Banda (1907-1929), en la época de la Restauración, Vinaròs, Associació Cultural "Amics de Vinaròs".

Artís I BenACH, P. (1999): «La naixença de l'Orfeó Català», dins DD.AA.: Clavé al cor: L'home i l'època, Barcelona, Diputació de Barcelona, 59.

AviñoA Pérez, X. (1999): «J. A. Clavé és mort», dins DD.AA.: Clavé al cor: L’home i l'època, Barcelona, Diputació de Barcelona, 58.

- (2000): Història de la Música Catalana, Valenciana i Balear, Barcelona, Edicions 62.

- (2000): «El moviment coral», dins AviñoA Pérez, X: Història de la Música Catalana, Valenciana

i Balear, Barcelona, Edicions 62, vol. Iv, 157-188.

Badenes Masó, G. (1992): Historia de la música de la Comunidad Valenciana, Alacant/València, Prensa Alicantina, Prensa Valenciana.

Balbás y Cruz, J.A. (1892): El Llibro de la Provincia de Castellón, Castello, Imp. de José Armengot.

Borrás JARQUE, J.M. (1979): Història de Vinaròs, Vinaròs, Associació Amics de Vinaròs.

Carbonell i Guberna, J. (1994): «Los Coros de Clavé. Un ejemplo de música en Sociedad», Bulletin d'histoire contemporaine de l'Espagne, 20, 68-78.

- (1999): «La Fraternidad», dins DD.AA.: Clavé al cor: L'home i l'època, Barcelona, Diputació de Barcelona, 28.

- (1999): «Els grans festivals», dins DD.AA.: Clavé al cor: L'home i l'època, Barcelona, Diputació de Barcelona, 36.

- (2000): «El cant coral», dins AviñoA Pérez, X.: Història de la Música Catalana, Valenciana i Balear, Barcelona, Edicions 62, vol. III, 147-186. 
- (2000): Josep Anselm Clavé i el naixement del cant coral a Catalunya (1850-1874), Cabrera de Mar, Galerada.

Casares Rodicio, E. (1999): Diccionario de la música Española e Hispanoamericana, Madrid, Sociedad General de Autores y Editores.

- (2006): Diccionario de la música Valenciana, Madrid, Iberautor Promociones Culturales.

DD.AA. (1999): Clavé al cor: L'home i l'època, Barcelona, Diputació de Barcelona.

GALBIS LóPEZ, V. (1992): «La música instrumental y vocal de la primera mitad del siglo XIX», dins BADENES MAsó, G. i altres: Historia de la música de la Comunidad Valenciana, Alacant/València, Prensa Alicantina, Prensa Valenciana, 241-260.

- (1999): «Pérez Gascón, Pascual», dins Casares Rodicio, E.: Diccionario de la música Española e Hispanoamericana, Madrid, Sociedad General de Autores y Editores, vol. 8, 647-649.

- (2000): «El cant coral al País Valencià», dins AviñoA Pérez, X.: Història de la Música Catalana, Valenciana i Balear, Barcelona, Edicions 62, vol. v, 109-118.

- (2006): «Coros», dins Casares Rodicio, E.: Diccionario de la música Valenciana, Madrid, Iberautor Promociones Culturales, vol. I, 253-261.

Gargallo i Domínguez, J. (2007): «Josep Anselm Clavé, músic, poeta i sociòleg», Cantem, 17, 16-19.

Gómez Acebes, A. (1994): «La Coral "El Maestrazgo" en el Festival de Clavé de 1864», Vinaròs, 24 de desembre, 43.

GuANSÉ I SAlesas, D. (1966): Josep Anselm Clavé: apòstol, agitador i artista, Barcelona, Bruguera.

Martínez de Sas, M.T. i P. Pagés I Blanch (2000): Diccionari biogràfic del moviment obrer als països catalans, Barcelona, Publicacions de l'Abadia de Montserrat.

Mestres i OÑós, A. (1876): Josep Anselm Clavé, sa vida i ses obres, Barcelona, Est.Tip. Espasa Germans i Salvat.

Mundina Milallave, B. (1873): Historia, Geografía y Estadística de la provincia de Castellón, Castelló, Imp. de Rovira Hermanos.

Nagore Ferrer, M. (1995): «La música coral en España en el s. XiX», dins Casares Rodicio, E. i C. Alonso González (eds.): La música en España en el s. XIX, Oviedo, Universidad de Oviedo, 425-462. - (1998): «Aportaciones al estudio del movimiento coral en España», dins AviÑoA PÉrez, X. (ed.): Miscel-lània Oriol Martorell, Barcelona, Universitat de Barcelona, 345-358.

- (1999): «Coros», dins Casares Rodicio, E.: Diccionario de la música Española e Hispanoamericana, Madrid, Sociedad General de Autores y Editores, vol. 4, 22-35.

- (2001): «Un aspecto del asociacionismo musical en España: las sociedades corales», Cuadernos de música iberoamericana, vol. 8-9, 211-225.

Poblet i Guarro, J.M. (1973): Josep Anselm Clavé i la seva època (1824-1874), Barcelona, Dopesa.

Ripollés Mansilla, A.F. (2004): Vicent García Julbe. Estudi i catalogació de la seua obra, Vinaròs, Ajuntament de Vinaròs.

Soriano Fuertes, M. (1865): Memoria sobre las sociedades corales en España, Barcelona, Imp. Narciso Ramírez.

TOMÁs Vert, I. (1992): «El movimiento coral valenciano», dins Badenes Masó, G. i altres: Historia de la música de la Comunidad Valenciana, Alacant/València, Prensa Alicantina, Prensa Valenciana, 451-460.

Torres Mulas, J. (1982): «El origen de los orfeones y sociedades corales en España», Cuadernos de Música, Madrid, any I, n. 2, oct., 79-91.

Trenc Ballester, É. (1994): «La Renaixença et l'implantation du chant choral à Lérida», Bulletin d'histoire contemporaine de l'Espagne, 20, 79-93.

VinYes, R. (1999): «El pensament polític de Clavé», dins DD.AA.: Clavé al cor. L'home i l'època, Barcelona, Diputació de Barcelona, 54. 


\section{BIONOTA}

\section{Arantxa Martínez Gavara}

Ha finalitzat els Estudis Superiors de Piano i Música de Cambra amb la professora Marisa Blanes, així com el Superior de Cant amb la soprano Gloria Fabuel. També és Professora Superior de Solfeig, Teoria de la Música, Transposició i Acompanyament. Està en possessió del Diploma d'Estudis Avançats (DEA) del Programa de Doctorat en Música de la Universitat Politècnica de València i continua amb la tesi doctoral sobre el moviment coral a la província de Castelló a la Universitat Jaume I de Castelló sota la direcció d'Antoni Ripollés. És membre titular del Cor de la Generalitat Valenciana. 